\title{
Paul Scarron, L'Écolier de Salamanque ou Ies Généreux Ennemis
}

\section{Cristina Bernazzoli}

\section{Q OpenEdition}

1 Journals

\section{Edizione digitale}

URL: https://journals.openedition.org/studifrancesi/39276

DOI: 10.4000/studifrancesi.39276

ISSN: 2421-5856

\section{Editore}

Rosenberg \& Sellier

\section{Edizione cartacea}

Data di pubblicazione: 1 décembre 2004

Paginazione: 360

ISSN: 0039-2944

\section{Notizia bibliografica digitale}

Cristina Bernazzoli, «Paul Scarron, L'Écolier de Salamanque ou les Généreux Ennemis», Studi Francesi [Online], 143 (XLVIII | II) | 2004, online dal 30 novembre 2015, consultato il 19 mai 2021. URL: http:// journals.openedition.org/studifrancesi/39276 ; DOI: https://doi.org/10.4000/studifrancesi.39276

Questo documento è stato generato automaticamente il 19 mai 2021.

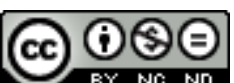

Studi Francesi è distribuita con Licenza Creative Commons Attribuzione - Non commerciale - Non opere derivate 4.0 Internazionale. 


\title{
Paul Scarron, L'Écolier de Salamanque ou Ies Généreux Ennemis
}

\author{
Cristina Bernazzoli
}

\section{NOTIZIA}

P. SCARRON, L'Écolier de Salamanque ou Ies Généreux Ennemis, texte établi, presente et annoté par ROGER GUICHEMERRE, Paris, Les Belles Lettres, 2003 («Société des Textes Français Modernes» 232), pp. 136.

1 Terza pièce di Scarron appartenente a questa prestigiosa collana (dopo Dom Japhet d'Armenie $\mathrm{n}^{0} 143$, e L'Héritier ridicule, $\mathrm{n}^{0} 176$ ), l'Écolier de Salamanque ou les Généreux Ennemis (tragicommedia edita a Parigi nel 1655 presso A, de Sommaville) è anch'essa un adattamento più o meno fedele di una comedia spagnola: trattasi, in questo caso, di Obligados y Ofendidos (1641) di Francisco de Rojas Zorrilla.

2 Dopo un attento esame dell'azione-complessa e ricca di peripezie drammatiche, caratterizzata da un doppio intrigo amoroso- e dei personaggi (i due eroi animati entrambi da nobili sentimenti, quali il coraggio, la generosità, il senso dell'onore; più sfumate le protagoniste femminili; ben inquadrate invece le figure dei domestici), ROGER GUICHEMERRE analizza il modello al fine di individuare successivamente l'originalità del rifacimento francese rispetto ad esso. Il critico osserva infatti che Scarron non solo ha modificato sensibilmente il dénouement, variato alcune scene, alleggerito dialoghi e lunghe tirate, ma soprattutto ha notevolmente sviluppato la parte comica, prestando al servitore Crispin, con i tratti tradizionali del gracioso spagnolo, un linguaggio «bouffon et bigarré». Egli inoltre - rileva ancora lo studioso - ha saputo elevarsi all'alto stile tragico in episodi drammatici laddove gli eroi sono inferiormente combattuti tra il desiderio di vendetta ed il rispetto della parola data.

Se l'espressione "grand auteur tragique» (p. xxx) può forse apparire un po' eccessiva, sicuramente la marca inconfondibile dell'autore del Virgile travesti ha dato ottimi risultati, consentendo a Scarron di aggiudicarsi la palma del miglior rifacitore della 
pièce di Zorrilla, imitata in quegli stessi anni da altri due noti drammaturghi francesi, Boisrobert (Les Généreux Ennemis) e Thomas Comeille (Les Illustres Ennemis). 